\title{
Polyoma Pseudovirions
}

\section{Influence of Host Cell on Pseudovirus Production}

\author{
DAVID B. YELTON ${ }^{1}$ AND $H$. VASKEN APOSHIAN \\ Department of Cell Biology and Pharmacology, University of Maryland School of Medicine, Baltimore,
} Maryland 21201

Received for publication 6 July 1973

\begin{abstract}
The type of host cell influenced the relative amounts of pseudovirions and polyoma virions produced. The infection of primary mouse embryo cells resulted in the production of particles that were predominantly pseudovirions. Infection of baby mouse kidney or 3T3D cells yielded mainly infectious polyoma virus. The length of time that infection was allowed to continue also affected the amount of pseudovirions relative to polyoma virions. The longer the viral infection was allowed to proceed, the greater the quantity of pseudovirions produced. Pseudovirion production could be correlated with the fragmentation of host cell DNA to a size of approximately $3 \times 10^{8}$ daltons. The fragmentation of host cell DNA was much more extensive in primary mouse embryo cells than in the other cell types.
\end{abstract}

Polyoma pseudovirions contain doublestranded, linear fragments of host cell DNA encapsidated within polyoma protein coats (13, $20)$. They are produced during polyoma infection of baby mouse kidney (BMK) cells $(13,20)$, primary mouse embryo (PME) cells (14), and mouse-hamster somatic cell hybrids (2).

Based on the proportion of DNA that hybridized with mouse DNA, Winocour (21) estimated that 16 to $21 \%$ of the virions produced during polyoma infection of mouse kidney cells contain fragments of host DNA. Michel et al. (13) have reported that most of their polyoma virus preparations grown in baby mouse kidney cells contained between 1 to $20 \%$ type III DNA; however, 12 out of 42 of their viral preparations contained between 60 and $90 \%$ type III DNA. Basilico and Burstin (2) have demonstrated that the DNA extracted from purified virus grown in a mouse-hamster hybrid cell line consists of about $10 \%$ supercoiled polyoma DNA molecules and approximately $90 \%$ linear DNA molecules that appear to be of cellular origin. After the infection of primary mouse embryo cells by polyoma virus, $80 \%$ or more of the complete particles harvested $120 \mathrm{~h}$ postinfection are pseudovirions (22).

In this investigation, it is shown that the type of host cell influenced the amount of pseudovirus produced; infection of primary mouse embryo cells resulted in the production of large

\footnotetext{
${ }^{1}$ Present address: Department of Microbiology, West Virginia University Medical Center, Morgantown, W. Va. 26506.
}

amounts of pseudovirions, whereas infection of baby mouse kidney or 3T3D cells yielded predominantly polyoma virus. It is also demonstrated that the ratio of pseudovirus to polyoma virus was dependent upon the length of time that the infection was allowed to proceed and was related to the amount of host cell DNA fragments found intracellularly during infection.

\section{MATERIALS AND METHODS}

Medium and reagents. Dulbecco's modified Eagle medium containing $10 \%$ calf serum (Gibco) was used. ${ }^{3} \mathrm{H}$-thymidine $(20 \mathrm{Ci} / \mathrm{mmol})$ was purchased from the New England Nuclear Corp. Receptor-destroying enzyme was obtained from Microbiological Associates, Inc. Standard saline citrate (SSC) contained $0.15 \mathrm{M}$ $\mathrm{NaCl}$ and $0.015 \mathrm{M}$ sodium citrate at $\mathrm{pH}$ 7.0. Tris buffer contained in $\mathrm{g} /$ liter $\mathrm{NaCl}, 8 ; \mathrm{KCl}, 0.38$; $\mathrm{Na}_{2} \mathrm{HPO}_{4}, 0.1$; dextrose, 1 ; and Tris, 3; the $\mathrm{pH}$ was adjusted to 7.4 with $\mathrm{HCl}$. Phosphate-buffered saline (PBS) was prepared according to Dulbecco and Vogt (9).

Cells. PME were prepared from whole embryos taken from 15- to 17-day pregnant mice. BMK cells were prepared by using the kidneys from 12-day-old mice. Swiss White Webster mice, purchased from Carworth Farms, were used unless otherwise specified. The continuous cell line, 3T3D, was obtained from Claudio Basilico. The cells were grown in either $60-\mathrm{mm}$ or $150-\mathrm{mm}$ plastic petri dishes (Falcon).

Radioactive labeling of DNA. Viral DNA and cellular DNA were labeled by adding medium containing $5 \mu \mathrm{Ci}$ of ${ }^{8} \mathrm{H}$-thymidine per $\mathrm{ml}$ to the cells immediately after the 2 -h virus adsorption period. Cellular DNA was labeled before infection by adding to the cells, $24 \mathrm{~h}$ after seeding, medium containing 2.5 $\mu \mathrm{Ci}$ of ${ }^{3} \mathrm{H}$-thymidine per $\mathrm{ml}$. The radioactive medium was removed after 2 days, and the radioactivity was 
chased by adding medium containing unlabeled thymidine $(50 \mu \mathrm{g} / \mathrm{ml})$ and deoxycytidine $(10 \mu \mathrm{g} / \mathrm{ml})$. Two hours later, the medium was again removed, and the cells were infected as described below. After the 2-h adsorption period, complete medium, including the nonradioactive thymidine and deoxycytidine, was added. This is essentially the method used in this laboratory for pseudovirion production and is described in detail elsewhere (14).

Virus growth and purification. The small plaque variant of the Toronto strain of polyoma virus was used for these experiments. A virus stock was prepared from an isolated plaque by three serial passages in baby mouse kidney cells. The third passage was at a multiplicity of infection of 0.5 PFU/cell.

Experiments to study host cell DNA fragmentation and virus production were performed by infecting confluent monolayers of cells with the stock virus at a multiplicity of infection of 0.5 PFU/cell. The virus in Tris buffer was allowed to adsorb to the cell sheet for 2 $h$ at $37 \mathrm{C}$. The plates were rocked every $30 \mathrm{~min}$ to ensure even distribution of the virions. After adsorption, fresh medium was added, and incubation was continued at $37 \mathrm{C}$ in a humidified incubator containing $10 \% \mathrm{CO}_{2}-90 \%$ air.

Virus was harvested by scraping the infected cells from the plates with a Teflon policeman. The mixture of cells and medium was centrifuged at $250 \times g$ for 10 min. The supernatant fluid was saved. The cells were suspended in PBS and lysed by five cycles of freezing and thawing. The cell debris was then treated with receptor-destroying enzyme (RDE) $(40 \mathrm{U} / \mathrm{ml})$ for $3 \mathrm{~h}$ at $37 \mathrm{C}$. The pH of the suspension was raised to 8.5 by adding $\mathrm{NaHCO}_{3}$ (4). The mixture was incubated at $37 \mathrm{C}$ for an additional $30 \mathrm{~min}$. The cell debris was pelleted as described above, and the supernatant fluid was decanted and saved. The pellet was resuspended in PBS and the extraction repeated two more times. Finally, all of the supernatant fluids were combined and centrifuged for $3 \mathrm{~h}$ at $25,000 \mathrm{rev} / \mathrm{min}$ by using a Spinco 30 rator to pellet the virus. The viral pellets were suspended in $0.01 \mathrm{M}$ Tris- $0.06 \mathrm{M} \mathrm{KCl}$ at $\mathrm{pH}$ 7.5. $\mathrm{CsCl}$ was added to adjust the density of the solution to $1.3 \mathrm{~g} / \mathrm{ml}$. The virus was then further purified by equilibrium centrifugation (19).

Virus assays. Hemagglutination assays were performed in the standard manner by using guinea pig red blood cells (4). Plaque assays were performed by using secondary mouse embryo cells (7).

DNA extraction. The low-molecular-weight DNA was extracted from infected cells by the SDS-1M $\mathrm{NaCl}$ method described by Hirt (11). DNA was extracted from purified virus particles by treatment with Sarkosyl and phenol (15).

Gradients. Equilibrium centrifugations in $\mathrm{CsCl}$ were performed as previously described (22).

Preformed, alkaline, 5 to $20 \%$ sucrose gradients, $\mathrm{pH}$ 12.5 , containing $0.5 \mathrm{M} \mathrm{NaCl}$ were used for sedimentation analyses of the low-molecular-weight DNA in the supernatant fluids of the SDS- $1 \mathrm{M} \mathrm{NaCl}$ extracts as well as the DNA from virus particles. The gradients were centrifuged at $50,000 \mathrm{rpm}$ for $2 \mathrm{~h}$ at $4 \mathrm{C}$ in a Spinco SW 50.1 rotor. Preformed, neutral, 10 to $30 \%$ sucrose gradients were used to.determine the size of the pseudoviral DNA. The gradients were centrifuged at $35,000 \mathrm{rev} / \mathrm{min}$ for $20 \mathrm{~h}$ at $4 \mathrm{C}$ in a Spinco SW 41 rotor. The gradients were fractionated, and the radioactivity of each fraction was determined as previously described (22).

DNA-DNA hybridizations. Hybridizations were performed by using the membrane filter technique of Denhardt (6). Hybridizations were carried out at $65 \mathrm{C}$ in $3 \times \mathrm{SSC}$, as described previously (15).

\section{RESULTS}

Infection of mouse cells with polyoma virus induces the synthesis of host cell DNA $(8,18)$. Some of the newly synthesized cell DNA is found in polyoma pseudovirions $(13,21)$. When radioactive thymidine is added to mouse cells after infection with polyoma virus, both the infectious polyoma virions and the pseudovirions are radioactively labeled. The specific activity of the DNA found in these two types of particles is approximately the same when the radioactive label is added immediately after virus adsorption (22).

Influence of host cell and time of harvest on the relative amounts of polyoma DNA and pseudoviral DNA found in purified virus particles. Three mouse cell types that were permissive for polyoma infection were used to determine whether the type of host cell affected the outcome of the infection. Baby mouse kidney, 3T3D, and primary mouse embryo cells were infected with polyoma virus. Medium containing ${ }^{\mathbf{3}} \mathrm{H}$-thymidine was added after a 2 -h virus adsorption period. The virus particles produced by $96-\mathrm{h}$ postinfection were purified and their content of $53 S$ and $16 S$ DNA was determined by sedimentation through alkaline sucrose gradients (Fig. 1). The percentage of polyoma virus was determined by dividing the counts per min in the $53 S$ region by the sum of the counts per min in the $53 S$ and the $16 S$ regions; the percentage of pseudovirus was determined by dividing the counts per min of the $16 S$ region by the same sum. That the measurements of radioactivity in the $53 S$ and $16 S$ areas of such alkaline sucrose gradients were a valid method of determining the polyoma and pseudovirus content of purified radioactive polyoma particles was demonstrated by DNA-DNA hybridization (Table 1). By the hybridization method, pseudovirus represented 20, 37, and $63 \%$ of the particles produced in $3 \mathrm{~T} 3 \mathrm{D}, \mathrm{BMK}$, and PME cells, respectively. Analysis by sedimentation velocity in alkaline sucrose gradients gave values of 20,38 , and $69 \%$.

The amount of pseudovirus produced was influenced not only by the type of host cell, but also by the length of time that infection was allowed to proceed. When the particles har- 


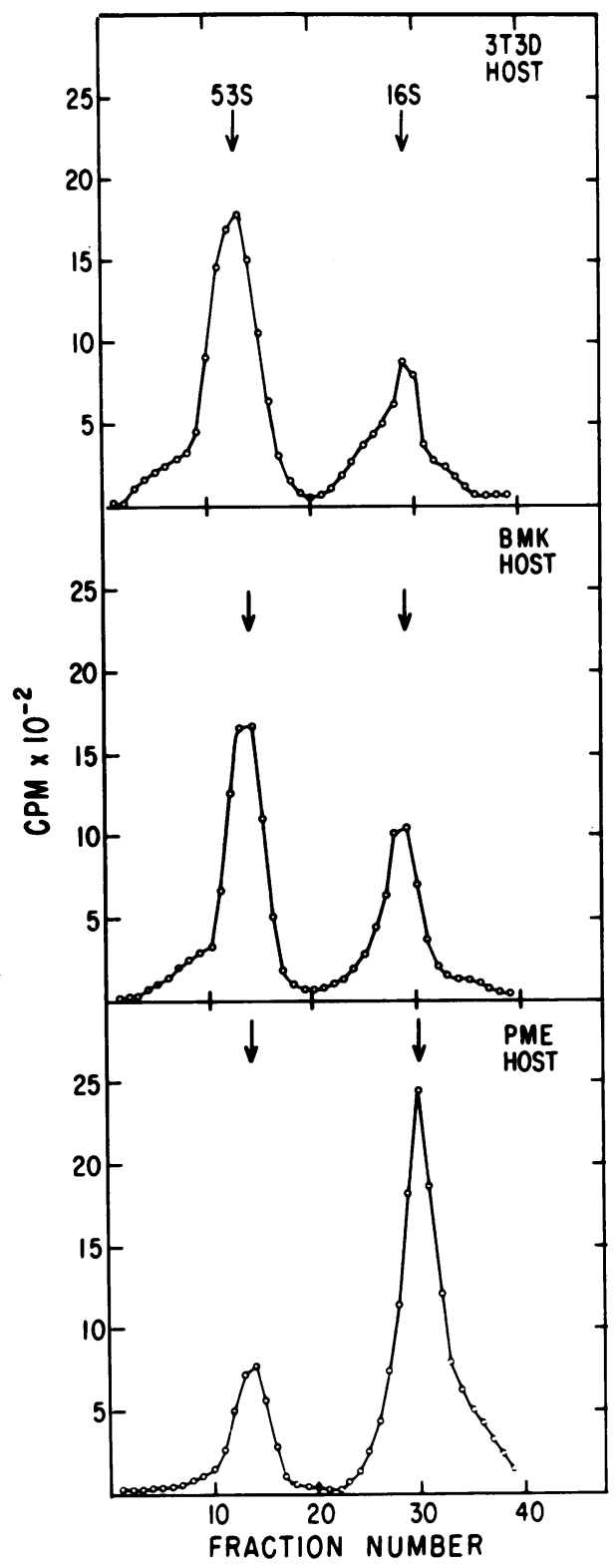

Fig. 1. The 53S and 16S DNA in virus particles purified from the different cell types $96 \mathrm{~h}$ after infection with polyoma virus. ${ }^{3} \mathrm{H}$-thymidine was added after the 2-h adsorption period. Virus was purified by two $\mathrm{CsCl}$ isopycnic centrifugations, after which it was centrifuged through neutral sucrose gradients as described in Materials and Methods. The purified virus particles were lysed in $0.3 \mathrm{~N} \mathrm{NaOH}$, layered onto alkaline 5 to $20 \%$ sucrose gradients, and centrifuged as described in Materials and Methods. The arrows represent the positions of ${ }^{14} \mathrm{C}-\mathrm{DNA}$ markers. vested from the BMK cells at different times after infection were analyzed by sedimentation in alkaline sucrose gradients, the relative proportion of pseudovirus produced increased from 16 to $38 \%$ between 48 and $96 \mathrm{~h}$ postinfection (Table 2). For 3T3D cells, the proportion increased from 15 to $20 \%$, and for PME cells, from 56 to $69 \%$ (Table 2).

Synthesis of polyoma DNA and fragmentation of host cell DNA. We have reported previously that large numbers of pseudovirions are produced during polyoma infection of PME cells and have suggested that this may be related to the quantity of host cell DNA which is fragmented (22). Because the ratio of polyoma virus to pseudovirus was different in the particles produced in BMK, 3T3D, and PME cells, the amount of host cell DNA fragmented after infection was determined for each of the cell types. In these experiments, medium containing ${ }^{3} \mathrm{H}$-thymidine was added immediately after virus adsorption. At 36,48 , and $60 \mathrm{~h}$ postinfection, the low-molecular-weight DNA was extracted from the cells by using the method described by Hirt (11) and analyzed by sedimentation in alkaline sucrose gradients. Table 3 summarizes data from the gradients as the percentage of polyoma DNA and percentage of $16 S$ host cell DNA found intracellularly at various times postinfection. After polyoma infection, some fragmentation of host cell DNA was found in the BMK and 3T3D cells, but it was not as extensive as that seen with the primary mouse embryo cells. In the PME cells, by $60 \mathrm{~h}$ postinfection, approximately $70 \%$ of the intracellular low-molecular-weight DNA sedimented at $16 S$ and was of cellular origin.

The strain of mouse does not appear to influence the production of $16 S$ host DNA fragments nor the synthesis of polyoma DNA. Extensive fragmentation of host cell DNA was seen only with the primary mouse embryo cells. Was this fragmentation dependent on the strain of mouse? Pregnant mice were obtained from three different supply houses, and the embryos were used to establish monolayers. The cells were infected and labeled with ${ }^{3} \mathrm{H}$-thymidine. At various times postinfection, the low-molecular-weight DNA was extracted and analyzed by sedimentation through alkaline sucrose. Extensive fragmentation of the host cell DNA after polyoma infection was found in primary mouse embryo cells derived from all three sources (Table 4). The strain of primary mouse embryo cells did not affect the relative amounts of polyoma DNA and host DNA fragments formed in the cells. 
TABLE 1. Determination by DNA-DNA hybridization of the relative proportions of polyoma DNA and host DNA found in purified polyoma $(P y)$ particles produced in different host cells

\begin{tabular}{|c|c|c|c|c|c|}
\hline \multirow{2}{*}{${ }^{3} \mathrm{H}-\mathrm{DNA}$ in solution } & \multirow{2}{*}{$\underset{\text { (counts } / \min )}{\text { Input }^{a}}$} & \multirow{2}{*}{$\begin{array}{l}\text { DNA immobilized } \\
\text { on filter }\end{array}$} & \multicolumn{2}{|c|}{ Hybridization } & \multirow{2}{*}{$\begin{array}{c}\text { Corrected values }^{a} \\
(\%)\end{array}$} \\
\hline & & & $\begin{array}{c}\text { Bound }^{c} \\
\text { (counts } / \mathrm{min} \text { ) }\end{array}$ & $\%$ & \\
\hline \multirow[t]{2}{*}{ Py DNA (Type I) } & 6,250 & Polyoma & 3,967 & 63.5 & 100 \\
\hline & 6,250 & Mouse embryo & 114 & 1.8 & 0 \\
\hline \multirow[t]{2}{*}{ PME DNA } & 21,930 & Polyoma & 652 & 3.0 & 0 \\
\hline & 21,930 & Mouse embryo & 5,796 & 26.4 & 100 \\
\hline \multirow[t]{2}{*}{ Py (3T3D) DNA } & 1,450 & Polyoma & 815 & 56.2 & 84 \\
\hline & 1,450 & Mouse embryo & 102 & 7.0 & 20 \\
\hline \multirow[t]{2}{*}{ Py (BMK) DNA } & 2,350 & Polyoma & 1,018 & 43.3 & 63 \\
\hline & 2,350 & Mouse embryo & 270 & 11.5 & 37 \\
\hline \multirow[t]{2}{*}{ Py (PME) DNA } & 1,910 & Polyoma & 451 & 23.6 & 32 \\
\hline & 1,910 & Mouse embryo & 351 & 18.4 & 63 \\
\hline
\end{tabular}

${ }^{a}$ Values represent the average of three filters in the linear region of a DNA-DNA hybridization curve.

${ }^{\circ}$ Py DNA $(2 \mu \mathrm{g})$ or PME DNA $(5 \mu \mathrm{g})$.

${ }^{c}$ Values represent the average of three filters in the linear region of a DNA-DNA hybridization curve and are corrected for nonspecific binding to blank filters.

${ }^{d}$ Calculated on the basis of the efficiency of the homologous reaction after subtraction of the value obtained in the heterologous reaction. This heterologous reaction is presumably due to mouse DNA which was not completely separated from the Py DNA by ethidium bromide-CsCl equilibrium centrifugation.

${ }^{e}$ Supercoiled Py DNA purified by centrifugation in ethidium bromide- $\mathrm{CsCl}$ density gradient.

TABLE 2. Relative amounts of polyoma DNA and pseudovirus DNA found in virus particles harvested at different times postinfection

\begin{tabular}{l|c|c|c}
\hline Cell type & $\begin{array}{c}\text { Time }(\mathrm{h}) \text { of } \\
\text { harvest }\end{array}$ & $\begin{array}{c}\text { \% polyoma } \\
\text { DNA }\end{array}$ & $\begin{array}{c}\text { \% pseudoviral } \\
\text { DNA }\end{array}$ \\
\hline BMK & 48 & 84 & 16 \\
& 72 & 70 & 30 \\
& 96 & 62 & 38 \\
3T3D & 48 & 85 & 15 \\
& 72 & 84 & 16 \\
& 96 & 80 & 20 \\
PME & 48 & 44 & 56 \\
& 72 & 32 & 68 \\
& 96 & 31 & 69 \\
\hline
\end{tabular}

${ }^{a}$ Each set of values represents the average of two or more experiments using a different batch of cells. The cells were infected at a multiplicity of infection of 0.5 $\mathrm{PFU} /$ cell and labeled with $5 \mu \mathrm{Ci}$ of ${ }^{3} \mathrm{H}$-thymidine per $\mathrm{ml}$ immediately following the 2 -h adsorption period. Virus was harvested, purified, and analyzed by sedimentation in alkaline 5 to $20 \%$ sucrose gradients as described in Fig. 1.

Does the cell type influence the size of pseudoviral DNA? The size of the pseudoviral DNA was determined by sedimentation of the DNA through neutral sucrose gradients (Fig. 2). The DNA extracted from pseudovirions grown in each of the cell types sedimented at approximately $14 S$, and each of the peaks was unimodal. Most of the pseudoviral DNA molecules, therefore, had a molecular weight of about $3 \times$ $10^{6}$, regardless of which cell type served as host for polyoma infection.

\section{DISCUSSION}

Three conclusions can be drawn from these experiments. First, the host cell influences the relative amounts of pseudovirions and polyoma virions produced during polyoma infection (Fig. 1, Table 1). Second, the longer the period of infection, the greater the proportion of pseudo-

TABLE 3. Relative amounts of polyoma DNA and fragmented host cell DNA (16S) found intracellularly at different times postinfection ${ }^{a}$

\begin{tabular}{c|c|c|c}
\hline Cell type & $\begin{array}{c}\text { Time }(\mathrm{h}) \text { of } \\
\text { harvest }\end{array}$ & $\begin{array}{c}\text { Polyoma } \\
\text { DNA }(\%)\end{array}$ & $\begin{array}{c}\text { Host cell } \\
\text { DNA (\%) }\end{array}$ \\
\hline BMK & 36 & 97 & 3 \\
& 48 & 94 & 6 \\
3T3D & 60 & 82 & 18 \\
& 36 & 98 & 2 \\
& 48 & 98 & 2 \\
PME & 60 & 94 & 6 \\
& 36 & 90 & 10 \\
& 48 & 52 & 48 \\
& 60 & 33 & 67 \\
\hline
\end{tabular}

${ }^{a}$ Each set of values represents the average of two or more experiments using a different batch of cells. Multiplicity of infection, labeling conditions, and centrifugation are as described in Table 2. 
TABLE 4. Relative amounts of polyoma DNA and $16 S$ mouse DNA found intracellularly after polyoma infection are independent of the source of the mouse embryo cells

\begin{tabular}{|c|c|c|c|c|c|c|}
\hline \multirow{3}{*}{$\begin{array}{l}\text { Time cells } \\
\text { were har- } \\
\text { vested after } \\
\text { infection }(h)\end{array}$} & \multicolumn{6}{|c|}{ Source of mice } \\
\hline & \multicolumn{2}{|c|}{$\begin{array}{c}\text { Carworth } \\
\text { Farms (CFW) }\end{array}$} & \multicolumn{2}{|c|}{$\begin{array}{l}\text { Flow Labs } \\
\text { (DUB/ICR) }\end{array}$} & \multicolumn{2}{|c|}{$\begin{array}{l}\text { Charles River } \\
\text { (CD-1) }\end{array}$} \\
\hline & $53 S^{a}$ & $16 S$ & $53 S$ & $16 S$ & $53 S$ & $16 S$ \\
\hline 36 & 80 & 20 & 70 & 30 & 70 & 30 \\
\hline 48 & 42 & 58 & 43 & 57 & 40 & 60 \\
\hline 60 & 26 & 74 & 30 & 70 & 29 & 71 \\
\hline
\end{tabular}

a Polyoma 53S and mouse DNA $16 S$ fragments were measured as the ${ }^{3} \mathrm{H}$-radioactivity cosedimenting with $53 S$ type I polyoma DNA ${ }^{14} \mathrm{C}$ marker and $16 S$ mouse DNA ${ }^{14} \mathrm{C}$ marker, respectively, in an alkaline 5 to $20 \%$ sucrose gradient. Values represent percentage of DNA.

virions produced (Table 2). Third, the larger the amount of host cell DNA fragments (16S) relative to polyoma DNA molecules found in the intracellular pool of low-molecular-weight DNA, the larger the proportion of pseudovirions relative to polyoma virions produced by the cell (Tables 2, 3).

The relative amounts of polyoma virus and pseudovirus produced were affected by the type of host cell used to grow the virus. The primary cells, PME, and BMK, produced a larger percentage of pseudovirus than the continuous cell line, 3T3D. Other investigators have also noticed a host cell effect on the outcome of polyoma and simian virus 40 (SV40) infection.

Basilico and Burstin (2) have reported a mouse-hamster hybrid cell line which produces almost entirely pseudovirions following polyoma infection. Even though no intracellular pool of fragmented host cell DNA was found in these hybrid cells, $90 \%$ of the complete particles were pseudovirions. Unlike the cells used in the present paper, however, in which polyoma DNA replication was normal, the mouse-hamster hybrid cells greatly restricted the replication of polyoma DNA.

Levine and Teresky (12) found variations in SV40 pseudovirus production after SV40 infection of three monkey cell lines. Pseudovirions were produced in only primary AGMK cells and not in the BSC-1 or CV-1 cells. Synthesis of cellular DNA was induced following SV40 infection of AGMK and CV-1 cells; however, excision of cellular DNA from the genome was seen only with the AGMK cells (17).

In the experiments reported in this paper, induction of host cell DNA synthesis as well as its excision or fragmentation occurred in all three cell types following infection with polyoma virus. When ${ }^{3} \mathrm{H}$-thymidine was added after virus adsorption, not only was the polyoma DNA labeled, but also the host cell DNA became radioactive, indicating that an induction of host cell DNA synthesis had occurred in the confluent monolayers. When the host cell DNA was radioactively labeled before polyoma infection, fragments of this radioactive cellular DNA were found in the pseudovirions produced

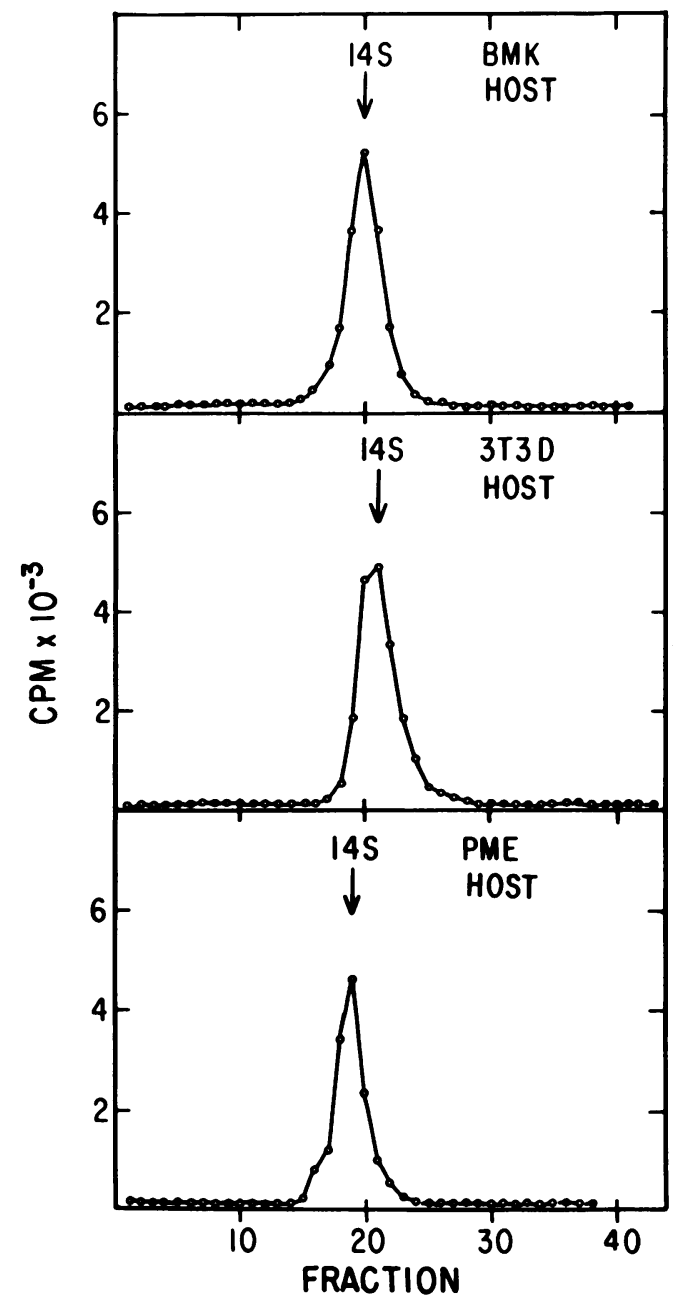

Fig. 2. Size of DNA in pseudovirions obtained after polyoma infection of BMK, 3T3D, or PME cells. The cells were labeled with ' $\mathrm{H}$-thymidine before infection. Virus was harvested at $96 \mathrm{~h}$ postinfection and purified as described in Materials and Methods. The DNA was extracted and sedimented through neutral 10 to $30 \%$ sucrose gradients as described in Materials and Methods. ${ }^{14} \mathrm{C}-\mathrm{DNA}$ with a sedimentation coefficient of $14 S$ was used as a marker. 
during infection. Thus, a process of excision or fragmentation was active in each of the cell types.

Michel et al. (13) found wide variation in the proportion of pseudovirus produced in BMK cells. It should be noted that, of the cell types we used, BMK cells showed the greatest variability in the proportion of pseudovirus produced. In five different experiments, the proportion varied from 26 to $54 \%$. This variation appeared to be related to the number of fibroblastic cells in the monolayer. Initially, almost all the cells were epithelial-like, but as the infection proceeded and the epithelial-like cells rounded up and detached from the dish, more fibroblastic cells appeared. The earlier the appearance of fibroblastic cells, the greater was the final proportion of pseudovirions. Mouse embryo cells which gave the greatest proportion of pseudovirions are predominantly fibroblastic cells from the outset. Although 3T3D cells are fibroblastic, they are also a continuous cell line, and if fibroblastic cells are indeed related to pseudovirus production, this particular line may have lost the required property for pseudovirus production during its selection.

Our data and those discussed above reaffirm the importance of the host cell in determining the outcome of the virus-cell interaction. Although it is commonly known that some cell types are refractory to infection by polyoma, others are transformed by polyoma, and still others are susceptible to lytic infection, not much attention has been paid to the differences in lytic infections which are attributable to the host cell. The data presented here show that the proportion of pseudovirus produced during lytic infection was influenced by the choice of host cell. This host cell effect was also seen in the fragmentation of the host cell genome to pseudoviral DNA size. Whether these variations reflect some genetic difference between the cell types or are merely indicative of differences in the physiological states is unknown.

Prolonging the period of infection led to an increased proportion of pseudovirions in the virus preparation. The reason for this is unclear, although it may be related to the type of DNA available for packaging. Replication of polyoma DNA is completed by about $36 \mathrm{~h}$ postinfection (22), whereas fragmentation of host cell DNA continues until much later (this paper; 3,22 ). Thus, at later times postinfection, an increasingly larger percentage of the low-molecularweight DNA (the size encapsidated by polyoma virus protein) is of host cell origin, and the result could be an increased production of pseudovirions.

The mechanism of production of $16 S$ fragments of host cell DNA represents an intriguing problem. Ben-Porat and Kaplan (3) have suggested that the host cell DNA synthesized following polyoma infection is defective and eventually breaks down into $16 S$ fragments. However, alternate explanations are possible. Babiuk and Hudson (1) and Ralph and Colter (16) have reported that polyoma DNA is integrated into the host cell genome during lytic infection. Mistakes in the polyoma excision mechanism could lead to the production of $16 S$ host cell fragments. Alternatively, disintegration of the nuclear membrane "late" in infection could allow cytoplasmic nucleases to act upon the cellular DNA. Interaction of $16 S$ host cell DNA fragments with viral proteins would protect these fragments from further nuclease action. Or finally, a nuclease, perhaps the polyoma-associated endonuclease (5), could specifically cut the cellular DNA at precise intervals. A nuclease activity from rat cells that has the ability to cut chromatin at specific intervals has recently been described (10). Which, if any, of these explanations is correct is yet to be determined.

\section{ACKNOWLEDGMENTS}

We gratefully acknowledge the excellent technical assist. ance of Maybritt Liden and Ronald Thayer.

This investigation was supported by Public Health Service grant GM-19209 from the National Institute of General Medical Sciences, grant CA-10497 from the National Cancer Institute, and grants from The John A. Hartford Foundation, Inc., the National Cystic Fibrosis Research Foundation, and the American Cancer Society, Inc., Maryland Division.

\section{LITERATURE CITED}

1. Babiuk, L. A., and J. B. Hudson. 1972. "Integration" of polyoma virus DNA into mammalian genomes. Biochem. Biophys. Res. Commun. 47:111-118.

2. Basilico, C., and S. J. Burstin. 1971. Multiplication of polyoma virus in mouse-hamster somatic hybrids: a hybrid cell line which produces viral particles containing predominantly host deoxyribonucleic acid. J. Virol. 7:802-812.

3. Ben-Porat, T., and A. S. Kaplan. 1967. Correlation between replication and degradation of cellular DNA in polyoma virus-infected cells. Virology 32:457-464.

4. Crawford, L. V. 1969. Purification of polyoma virus, p. 75-81. In K. Habel and N. P. Salzman (ed.), Fundamental techniques in virology. Academic Press Inc., New York.

5. Cuzin, F., D. Blangy, and P. Rouget. 1971. Activité endonucléasique de préparations purifées du virus du Polyome. C. R. Acad. Sci. 273:2,650-2,653.

6. Denhardt, D. T. 1966. A membrane filter technique for the detection of complementary DNA. Biochem. Biophys. Res. Commun. 23:641-646.

7. Dulbecco, R., and G. Freeman. 1959. Plaque production 
by polyoma virus. Virology 8:396-397.

8. Dulbecco, R., L. H. Hartwell, and M. Vogt. 1965. Induction of cellular DNA synthesis by polyoma virus. Proc. Nat. Acad. Sci. U.S.A. 53:403-410.

9. Dulbecco, R., and M. Vogt. 1954. Plaque formation and isolation of pure lines with poliomyelitis virus. J. Exp. Med. 99:167-182.

10. Hewish, D. R., and L. A. Burgoyne. 1973. Chromatin substructure. The digestion of chromatin DNA at regularly spaced sites by a nuclear deoxyribonuclease. Biochem. Biophys. Res. Commun. 52:504-510.

11. Hirt, B. 1967. Selective extraction of polyoma DNA from infected mouse cell cultures. J. Mol. Biol. 26:365-369.

12. Levine, A. J., and A. K. Teresky. 1970. Deoxyribonucleic acid replication in simian virus 40 -infected cells. II Detection and characterization of simian virus 40 pseudovirions. J. Virol. 5:451-457.

13. Michel, M. R., B. Hirt, and R. Weil. 1967. Mouse cellular DNA enclosed in polyoma viral capsids (pseudovirions). Proc. Nat. Acad. Sci. U.S.A. 58:1381-1388.

14. Osterman, J. V., A. Waddell, and H. V. Aposhian. 1970 DNA and gene therapy: uncoating of polyomapseudovirions in mouse embryo cells. Proc. Nat. Acad. Sci. U.S.A. 67:37-40.

15. Qasba, P. K., and H. V. Aposhian. 1971. Transfer of mouse DNA to human and mouse embryonic cells by polyoma pseudovirions. Proc. Nat. Acad. Sci. U.S.A. 68:2345-2349.

16. Ralph, R. K., and J. S. Colter. 1972. Evidence for the integration of polyoma virus DNA in a lytic system. Virology 48:49-58.

17. Ritzi, E., and A. J. Levine. 1970. Deoxyribonucleic acid replication in simian virus 40 -infected cells. III. Comparison of simian virus 40 lytic infection in three different monkey kidney cell lines. J. Virol 5:686-692.

18. Weil, R., M. R. Michel, and G. K. Ruschmann. 1965. Induction of cellular DNA synthesis by polyoma virus. Proc. Nat. Acad. Sci. U.S.A. 53:1468-1475.

19. Winocour, E. 1963. Purification of polyoma virus. Virology 19:158-168.

20. Winocour, E. 1967. Studies on the basis for the observed homology between DNA from polyoma virus and DNA from normal mouse cells, p. 577. In J. S. Colter and W. Paranchych (ed.), The molecular biology of viruses. Academic Press Inc., New York.

21. Winocour, E. 1968. Further studies on the incorporation of cell DNA into polyoma-related particles. Virology 34:571-582

22. Yelton, D. B., and H. V. Aposhian. 1972. Polyoma pseudovirions. I. Sequence of events in primary mouse embryo cells leading to pseudovirus production. J. Virol. 10:340-346. 